\title{
CURRÍCULO, SABERES E VIVÊNCIAS DOS PROFESSORES DA EJA: Reconfigurações em uma escola de assentamento
}

\author{
Divoene Pereira Cruz \\ Rosa Aparecida Pinheiro ${ }^{(*)}$
}

Pensar as proposições curriculares para a educação de jovens e adultos em um assentamento, a partir dos saberes e das vivências dos professores da EJA, constitui uma tarefa complexa na compreensão de valores e interesses, incluindo escolhas feitas por estes professores em seu cotidiano e os referenciais que adotam como norteadores. Ao reconhecerem sua identidade campesina, os professores que atuam em um contexto de exclusão social, na negação de direitos básicos de estrutura e formação, buscam formas de organização e elaboração de uma proposição curricular que respondam em suas intervenções aos anseios de seus companheiros educandos. Neste percurso, os professores relacionam suas práticas educativas à formação inicial e continuada no engajamento aos movimentos sociais, vislumbrando a possibilidade de desenvolvimento de outras experiências no cotidiano, no trabalho e na militância.

A investigação apresentada, com recorte temporal no período de 2014 e 2015, é centrada na Escola Municipal Francisca Leonísia, localizada no Assentamento Rural Serra Nova, município de Florânia /RN, reconhecida pelo poder público como instituição escolar no ano de 2001, tendo como órgão mantenedor a Secretaria Municipal de Educação. Ao se compreender o currículo da EJA a partir das possíveis influências e interferências dos saberes e das vivências dos professores do MST em sua relação com o sistema público de ensino, distingue-se a existência de duas lógicas que orientam a prática pedagógica na EJA da escola, uma encaminhada pela Secretaria Municipal de Educação e outra orientada pelo movimento social (MST).

\footnotetext{
${ }^{(*)}$ Divoene P. Cruz. Doutoranda pela Universidade Federal do Rio Grande do Norte (2015), mestra em Educação (2012) e licenciada em Pedagogia (2006) pela Universidade Federal do Rio Grande do Norte. Professora da Rede Municipal de Ensino em Florânia (RN), no Assentamento de Reforma Agrária Serra Nova. Currículo: <http://lattes.cnpq.br/5450633055305958>.

Rosa A. Pinheiro. Professora da Universidade Federal de São Carlos (UFSCar) e do PPGED da UFRN, com pesquisa no campo do Currículo e na Educação de Jovens e Adultos. Graduação em Pedagogia pela UFSCar. Mestrado em Educação pela Universidade Federal da Paraíba, doutorado em Educação pela UFRN com estágio doutoral na Universidad de Barcelona e Pós-doutorado na Universidade do Estado do Rio de Janeiro (UERJ). Currículo: $<$ http://lattes.cnpq.br/6292207464385037>.
} 
Nas reflexões dos professores, a proposição conduzida pela Secretaria Municipal, representaria uma visão institucional com preceitos burocráticos, enquanto a outra, advinda de um movimento social, apresentaria dinâmicas e propostas diferenciadas fundamentadas nos direitos sociais dos homens e das mulheres campesinas. A existência dessas lógicas produz descompassos na organização curricular e na prática pedagógica, em uma conjuntura que apresenta a existência de embates, contradições e desafios - que podem constituir limites para a implantação de um currículo crítico e emancipador no atendimento de demandas pessoais e profissionais dos sujeitos assentados.

Para entendermos estas relações, realizamos uma investigação fundamentada na Pesquisa Colaborativa, de caráter interpretativo/reflexivo, como opção metodológica que valoriza o aspecto qualitativo nas investigações de contextos educacionais, envolvendo circunstâncias sociais nas quais se insere a pesquisa. $\mathrm{Na}$ escolha por esta opção metodológica considerou-se a pertinência entre os princípios desta modalidade e as questões traçadas para uma possível reconfiguração curricular. Neste sentido, os princípios colaborativos da formação coletiva e coautoria no processo investigativo fortalecem o espaço democrático dos diálogos e das negociações empreendidas durante o processo. De acordo com Carr e Kemmis (1988, p. 199):

[...] a investigação colaborativa favorece o estabelecimento de comunidades autocríticas de educadores-investigadores que desenvolvem sistematicamente um saber educacional que justifica suas práticas, assim como as situações educativas construídas através destas práticas [...].

A colaboração possibilitou um espaço dialógico e democrático, no qual os sujeitos envolvidos construíram coletivamente uma reflexão autocrítica acerca de suas práticas pedagógicas e do currículo da EJA na escola locus desta investigação. Esse espaço se constituiu como fundamental para a abordagem dos saberes e das vivências dos professores assentados, no qual a formação coletiva propiciou aos sujeitos participantes a reflexão permanente quanto a sua participação na construção curricular da EJA. As ponderações acerca destes saberes e vivências permitiram a abordagem de aspectos relacionados à identidade dos professores, redimensionando a pesquisa como atividade humana e social, na qual a autorreflexão coletiva propicia um lugar comum para pensar as dificuldades encontradas no cotidiano da EJA do campo.

O princípio da colaboração tem como fundamento a individuação (na qual o indivíduo constrói sua autonomia na relação com o coletivo), no sentido de manter as escolhas e condutas de cada colaborador, e se diferencia de uma relação individualista que busca tão somente a satisfação de cada participante. (PINHEIRO, 2007, p. 39).

O grupo colaborador foi formado por seis professores que são também agricultores e agricultoras e que, durante a colheita, conciliam suas atividades docentes com o trabalho em seus lotes. Todos participaram com muito entusiasmo dos debates, tendo suas falas gravadas para 
posterior análise. Para a identificação dos registros dos depoimentos, houve o consenso de notificação, apenas, das iniciais dos mesmos.

O conjunto dos professores é comprometido com as questões políticas, econômicas e sociais da comunidade, desenvolvendo um trabalho relevante na luta por justiça social e participando ativamente das relações cotidianas da comunidade. $\mathrm{O}$ embate do grupo remonta desde a origem do assentamento, pois esses professores foram pioneiros na desapropriação do latifúndio e na criação do Povoado João da Cruz e, atualmente, exercem uma prática pedagógica que contribui para a consolidação do processo de formação escolar com uma postura de perseverança frente à problemática da organização curricular da EJA no assentamento.

No repensar de suas práticas, os professores assentados fazem reflexões sobre as conceituações e concepções inscritas nos referenciais curriculares, reconstruindo conceitos e sua identidade profissional como educadores de EJA do campo que atuam em condições desfavoráveis impostas à vida dos trabalhadores e trabalhadoras rurais. Neste repensar, nos debates do grupo colaborador, no aprofundamento das reflexões acerca das concepções sobre sua prática educativa, os professores demonstraram olhares diversos. Essas visões ainda apresentam resquícios de entendimentos curriculares fechados, os quais embasaram parte da formação desses professores no campo do currículo.

Currículo para mim é planejamento, organização... enfim é a coisa na escola bem organizada. O professor segue o currículo, o aluno cumpre com as atividades e tudo fica certo... Posso até ser antiga, mas eu ainda aposto na coisa certinha, planejada (Professora JF)

Currículo para mim é vida, é o dia-a-dia, é a escola, a nossa comunidade... Agora, a gente precisa organizar, sistematizar este currículo para que as aulas sejam mais proveitosas e que tenham como referência a vida dos nossos alunos. (Professora MS).

Em um contexto de conflitos, as visões dicotomizadas prescindem de uma reflexão coletiva que perceba o currículo para além de um conjunto conteudista, que assuma um caráter crítico e possibilite a valorização e o reconhecimento dos saberes e da identidade das pessoas jovens e adultas. Neste sentido, a EJA da escola do assentamento necessita se reafirmar em sua identidade que pressupõe, entre outros aspectos, a luta pelos direitos coletivos e a consolidação de uma organização curricular identitária para os sujeitos educandos da comunidade. Nessa escola, inicialmente, em 1997, por ocasião da desapropriação do latifúndio e criação da comunidade, havia necessidade do processo de alfabetização, que aconteceu na única casa existente, a casa da fazenda, lugar onde professores integrantes do movimento se responsabilizaram pelas aulas iniciais. $\mathrm{Na}$ alfabetização atendeu-se a aproximadamente cinquenta pessoas, as quais se acomodavam em um espaço físico inadequado, à luz de lamparinas e candeeiros. Somente no final de 2007, iniciou-se a 
construção do prédio próprio e em 2011, na EJA, no nível I, foram matriculados trinta alunos. Em 2013, a EJA alcançou o maior índice de matrícula, com setenta e oito alunos jovens e adultos, predominando entre os matriculados jovens, em sua maioria filhos de companheiros assentados. No entanto, nos anos seguintes, 2014 e 2015, houve um alto índice de evasão e atualmente há 45 alunos matriculados.

Para tentar reverter este quadro de abandono escolar, em suas falas, os professores remetem à necessidade de se promover mudanças na organização curricular e na prática cotidiana, observando-se recorrentemente a ideia de que o currículo precisa estar voltado para as demandas pessoais e profissionais dos alunos jovens e adultos.

Acho que a gente precisa elaborar nossas aulas a partir do que os alunos querem quando nos procuram e voltam à escola. Principalmente os adultos e pessoas idosas. Mas, acontece que os desejos e as necessidades das pessoas mudam com o tempo. Então, eu penso que esta questão é muito mais ampla do que somente preparar uma aula diferente. (Professora AI)

Eu pensava que os projetos, as aulas de campo que eu dava eram necessários para os alunos permanecerem na EJA. Descobri que não. Então, penso que cada um de nós precisa ter consciência de que as mudanças necessárias são maiores do que a gente faz isolado dos colegas dentro da sala de aula. (Professora MS).

Mediante a realidade controversa, os depoimentos apontam que não podemos esquecer nossos compromissos, enquanto educadores, de inaugurar e consolidar um processo dialógico e reflexivo, que possa contribuir com a construção de uma perspectiva curricular legítima e identitária que considere como princípio básico a emancipação e a autonomia na educação de jovens e adultos. Perante a relevância histórica e cultural da escola Francisca Leonísia, é justo que esta seja um lugar onde a luta por uma prática pedagógica crítica e emancipadora se constitua como um ideário coletivo. Desta forma, será respeitado o percurso dos trabalhadores e trabalhadoras rurais que tiveram seus direitos à educação negados e se mantiveram afastados da escola por exclusões sociais que necessitam ser superadas.

Sujeitos não se formam só na escola. Há outras vivências que produzem aprendizados até mais fortes. A Pedagogia do Movimento não cabe na escola, porque o Movimento não cabe na escola, e porque a formação humana também não cabe nela. Mas a escola cabe no Movimento e em sua pedagogia; cabe tanto que historicamente o MST vem lutando tenazmente para que todos os semterra tenham acesso a ela. A escola que cabe na Pedagogia do Movimento é aquela que reassume sua tarefa de origem: participar do processo de formação humana. (CALDART, 2004, p. 147).

Embora esta concepção se apresente como matriz da organização pedagógica, na discussão a respeito dos distanciamentos entre os referenciais curriculares e a realidade contextual da prática na EJA, inserida nos movimentos sociais, os professores se reportaram à ausência das matrizes 
pedagógicas do MST nesses referenciais. Em suas falas, as professoras MV e SF denunciam a ausência de espaços formativos plurais em que os coletivos específicos discutam suas diversidades.

[...] infelizmente, não é dada nós, professores assentados, a oportunidade de estudar os referenciais do Movimento. A gente fica muito distante das discussões do MST em virtude de precisarmos atender as diretrizes educacionais da escola municipal. (Professora MV).

Eu li muito pouco sobre essas matrizes. [...] Eu acho que não nos dão oportunidade de discutir isso nas formações. Aliás, não existe um curso de formação para professores assentados. Gostaria muito que a gente sentasse depois para estudar sobre isto. (Professora SF).

Os debates empreendidos nas sessões reflexivas corroboram a situação conflituosa existente no campo curricular e reafirmam a existência de duas lógicas que orientam o currículo da EJA da escola do assentamento. Um repensar coletivo se apresenta como ponto de partida para que os professores reconfigurem o currículo da EJA em uma perspectiva formativa e elaborem conjuntamente propostas que contemplem os direitos individuais e coletivos das pessoas jovens e adultas do campo. Este repensar, enquanto um exercício da prática cotidiana, exige dos professores o compromisso social que abarca o reconhecimento das demandas pessoais e profissionais dos sujeitos jovens e adultos.

Pensar a organização curricular de uma escola municipal inserida numa área de assentamento rural da Reforma Agrária pressupõe o entendimento dos diferentes e antagônicos interesses políticos que permeiam o processo de formação escolar. De um lado, o MST, numa perspectiva de reafirmar a sua luta em defesa dos direitos sociais; de outro, o Sistema Municipal de Educação representando o Estado, com uma concepção institucionalizada de escola, que tende a homogeneizar as questões relacionadas ao currículo. Cabe aos professores assentados, a partir da formação política e pedagógica, a compreensão de que mesmo estando inseridos numa instituição escolar do Estado, e com limitada autonomia, podem construir perspectivas críticas, qualificar e redesenhar uma nova instituição pública.

A formação política e pedagógica estimula uma postura de discernimento que os capacita a ultrapassar as barreiras impostas por uma estrutura curricular tradicional prescrita, no respeito às subjetividades das pessoas pertencentes a contextos desfavorecidos socialmente. A formação pedagógica e política no MST influencia na concepção de educação como atividade histórica e social, intrinsecamente política e problematizadora. Neste sentido, as contribuições desta formação consistem em possibilitar aos professores assentados a superação de visões acríticas e uma postura que fortaleça a identidade coletiva enquanto professores e sujeitos pertencentes aos movimentos sociais. 


\section{RECONFIGURAÇÃO CURRICULAR DA EJA NA ESCOLA DO ASSENTAMENTO FRANCISCA LEONÍSIA}

A trajetória da educação de jovens e adultos tem assumido ao longo da educação escolar perspectivas conceituais e práticas diferenciadas, as quais, em maioria, respaldadas nos interesses de grupos dominantes e que tem influenciado profundamente a elaboração das propostas educativas que orientam as ações dos professores e o currículo da EJA:

Historicamente, a educação de jovens e adultos vem assumindo concepções e práticas bastante diferenciadas. Da visão ainda muito corrente de que ela se faz para recuperar o tempo perdido daqueles que não aprenderam a ler e escrever; passando pelo resgate da dívida social; até chegar a concepção de direito à educação para todos da presente década, e do aprender por toda a vida, as enunciações variavam, deixando, no entanto, no imaginário social, a sua marca mais forte, ligada à volta à escola, para fazer, no tempo presente, o que não foi feito no tempo da infância. (PAIVA, 2005, p. 27).

Com esta demarcação, a EJA na escola do campo e, sobretudo a do MST, se depara com desafios, dentre os quais o de repensar a organização curricular e a prática dos professores a partir da história de vida desses trabalhadores e das suas trajetórias de luta. Ao se tratar das dificuldades que afetam sua prática docente é fundamental uma compreensão mais ampla acerca das negações vivenciadas na educação de jovens e adultos para que as dificuldades sejam superadas e não se configurem como mais um fator que distancia a realidade escolar da vida pessoal e profissional dos sujeitos.

No processo de ressignificação curricular a reflexão coletiva dos professores assume um dos desafios do MST, que “[...] está na articulação conjunta, resguardadas as diferenças, para a elaboração de propostas que possam ir para além da globalização econômica, que avance na direção de uma globalização social" (SOUZA, 2016, p. 14), com alianças entre os diferentes movimentos e iniciativas que estão resistindo e propondo alternativas criativas à exclusão social.

Quanto à perspectiva desta articulação, a respeito do lugar em que os saberes e as vivências construídos no MST ocupam no currículo, o grupo demonstrou reconhecer a importância destes na relação com suas práticas educativas no cotidiano da EJA, integrando-os à construção curricular.

Ah, os meus saberes eu valorizo e muito. Tanto os de professora como os da luta como assentada. Quando falamos das nossas experiências no MST e depois que nos tornamos assentados todos os alunos querem fazer um relato... lembram das dificuldades. (Professora MS).

A integração entre os saberes advindos das experiências individuais e coletivas e da realidade contraditória da organização curricular prescrita é possível a partir dos sentidos que os professores atribuem à sua tradição cultural, valores, modo de ser e viver num assentamento rural. 
Neste aspecto, a compreensão demonstrada por professores assentados sobre como integrar sua tradição cultural ao currículo foi elaborada nas práticas cotidianas na EJA. Nos assentamentos rurais a vida comunitária é o espaço onde os desejos e as necessidades individuais assumem o caráter coletivo, passando a ser uma luta de cada um e de todos. Esse caráter coletivo é assumido principalmente no seio das associações que representam os agricultores e agricultoras assentados e a força da vida comunitária, tornando-se também uma expressão de poder em como os aspectos comunitários são valorizados no dia-a-dia da EJA.

É muito importante trabalharmos a memória dos nossos alunos, pois é uma forma de resgatar a identidade do campo, dos antepassados, de como viviam nos sítios em que nasceram. Tudo isso pode nos ajudar até para juntar as diferentes faixas etárias. Afinal, quase todo mundo tem um laço de parentesco ou de amizade. É muito bom falar da memória deles. (Professora AI).

No depoimento são apresentadas facetas importantes da escolarização na EJA, como a possibilidade de esta ser um espaço no qual os jovens e adultos possam escrever sobre as suas próprias vidas. Desta forma, é reiterado o pensamento de que a EJA deve partir do conhecimento que os sujeitos trazem de suas trajetórias nas quais as experiências vividas não podem ser esquecidas pela escola, mas sim valorizadas. Outro aspecto diz respeito à busca pela escolarização que se respalda no desejo dos jovens e adultos em superarem a exclusão socioeconômica a partir da conquista de um trabalho melhor. Nesta direção, um desafio para os professores é mobilizar em suas práticas saberes que articulem a necessidade de formação à valorização da identidade dos sujeitos educandos do campo.

Nossos alunos têm muitos saberes. Os saberes populares, os religiosos, que envolvem rezas, curas de enfermidades. Os saberes da terra que proporciona saber onde plantar, o que plantar. (Professora JF).

Uma coisa que admiro muito é o saber da apicultura e a forma como a associação se organizou para vender o mel. É de dar orgulho na gente. Quando pergunto a eles sobre como vai a produção de mel eles explicam direitinho preço, quantidade que foi vendida e olhe que muitos sabem ler muito pouco. (Professora MS).

Na perspectiva freireana, (2007), os saberes pedagógicos se processam em relação com um educador democrático, viabilizando sua autonomia e dos sujeitos educandos. Esta visão é relacionada com o contexto no qual os professores assentados atuam e exercem a sua função social como mediadores de uma prática igualmente democrática, fundamentando processos reflexivos e abarcando subjetividades e atitudes dos envolvidos. Para Charlot (2000), o saber ocorre na coletividade, por meio da experiência de cada sujeito e nas atividades a que todos estão submetidos em sua valorização e apropriação. O saber se processa na relação que cada qual estabelece com o 
mundo e com os outros, sendo concebido enquanto conhecimento humano construído a partir das experiências coletivas.

Os saberes e as vivências dos professores assentados perpassam a realidade na qual estes estão inseridos se relacionando com os aspectos sociais, políticos e econômicos dos contextos em que vivem e atuam. Os saberes são produzidos a partir do conhecimento em suas vivências no cotidiano da luta na produção da terra e na ação educativa em sala de aula. A relação que os professores estabelecem com saberes existentes em suas práticas pedagógicas é fundamental para que reconfigurem o currículo ao reconhecer e valorizar a identidade dos educandos. Para tal, se faz necessário que os professores se reconheçam enquanto sujeitos sociais nas relações estabelecidas com as instituições educativas e o movimento social de pertencimento.

A partir desta percepção, no cotidiano da educação de jovens e adultos e da prática educativa nos assentamentos, os professores se posicionam acerca do que seria possível fazer para revertermos o quadro desestimulador da EJA na escola. Apesar de demonstrarem compreender os aspectos que constituem a problemática na qual estão inseridos, em suas falas se percebe uma mistura de sentimentos que exprime angústia, culpabilidade, visões discriminatórias e desânimo.

Ah... para mudar esse quadro é preciso muito mais do que nós podemos fazer. O que existe é falta de vontade de melhorar. Olhe a EJA já é discriminada e sendo num assentamento aí é maior a discriminação. O problema abrange muitos aspectos: o político e principalmente o econômico. (Professor SF).

Um desafio que os professores assentados enfrentam é fortalecer, no espaço oficial de ensino, uma proposta que incorpore os princípios políticos e pedagógicos do MST e que, ao mesmo tempo, o reconheça na diversidade da educação do campo. Desta forma, as experiências educacionais desenvolvidas pelos professores assentados nas escolas em que atuam podem ser enriquecidas em trocas significativas com os educandos que evidenciam as peculiaridades da identidade campesina, que supõe o convívio e a solidariedade. Neste universo cultural que é do outro, mas também seu, os professores estabelecem relações sociais com base em suas origens socioculturais e possibilitam interações que enriquecem as práticas pedagógicas. Os vínculos sociais são, portanto, aspectos importantes na construção de práticas educativas cotidianas, pois se ligam à cultura local e ao seu contexto social que precisam ser valorizados no currículo enquanto representações da identidade comunitária.

No imbricamento das duas lógicas que influenciam e orientam a configuração curricular da EJA na escola (da Secretaria Municipal de Educação e do MST), se pode pensar em uma realidade conflituosa e desafiante. Na reconfiguração, a partir destas duas lógicas, considera-se também a 
reflexão a respeito da Proposta Curricular da EJA (Secretaria Municipal de Educação) como referencial adotado pela escola e utilizado pelos professores como norteador da prática pedagógica.

Contudo, ao se encontrar uma realidade vivenciada no âmbito da elaboração e estruturação curricular nas instituições escolares, quando as propostas que deveriam legitimar os direitos dos sujeitos educandos se afastam de suas vidas e desconsideram as trajetórias escolares percorridas por estes, se percebe a contradição que se reflete nos significados atribuídos a estas propostas pelos sujeitos, sejam educandos ou educadores. Nesta visão, Silva (2007, p. 15) ressalta:

Nas discussões cotidianas, quando pensamos um currículo pensamos apenas em conhecimento, esquecendo-nos de que o conhecimento que constitui o currículo está inextricavelmente, centralmente, vitalmente, envolvido naquilo que somos, naquilo que nos tornamos: na nossa identidade, na nossa subjetividade.

$\mathrm{Na}$ EJA, quando os referenciais curriculares não legitimam a identidade dos sujeitos, estes, por sua vez, não os reconhecem como instâncias relevantes em suas trajetórias de formação escolar. Nas práticas curriculares do assentamento, em geral, os espaços de formação não oferecem oportunidades para os professores manifestarem seus saberes. Os encontros promovidos pelos órgãos municipais nem sempre significam possibilidade de parcerias ou ajuda mútua, pois muitos professores assentados se sentem reticentes na discussão de suas práticas, em virtude dos espaçamentos e descompassos apontados.

É registrada pelos professores a existência de múltiplas visões em torno dos referenciais curriculares da EJA que se encontram e se confrontam no que diz respeito à importância destes documentos como norteadores de suas práticas. Os debates do grupo evidenciam ausências e distanciamentos nos documentos que norteiam a educação de jovens e adultos na escola do assentamento, ausências que precisam ser repensadas numa perspectiva de superação para que as propostas curriculares aprofundem as questões específicas que perpassam a EJA. A superação das fragilidades evidenciadas na organização curricular perpassa a concepção de um currículo crítico para além de um conjunto de matérias ou determinações impostas, assumindo o reconhecimento e a valorização do saber construído na escola.

O legado das teorias curriculares críticas para a construção de um projeto educacional do campo, no tocante aos conceitos de ideologia e poder estão relacionados à conscientização, à libertação e à prática social de sujeitos constituintes de sua própria trajetória. Este projeto educativo se articula a uma prática pautada na valorização dos saberes e das vivências dos educandos, rompendo com as concepções hegemônicas que insistem em controlar a vida desses sujeitos e 
legitimar conhecimentos que corroboram demarcações particulares em detrimento dos interesses coletivos.

[...] as escolas não apenas controlam as pessoas; elas também ajudam a controlar o significado. Pelo fato de preservarem e distribuírem o que se percebe como "conhecimento legítimo" - o conhecimento legítimo que todos devemos ter — as escolas conferem legitimidade cultural ao conhecimento de determinados grupos. (APPLE, 2006, p. 104).

Em suas falas os professores ressaltam a importância de uma EJA que considere as histórias de vida dos jovens e adultos do campo, mas que também dê conta de atender as necessidades formativas que o mundo do trabalho atual lhes impõe. Esta questão se constitui como um desafio para os professores, que precisam mobilizar sujeitos educandos do campo que, tardiamente, tiveram acesso a uma escolaridade que desconsidera suas trajetórias de vida e que, na maioria das vezes, significou um distanciamento da sua cultura, dos seus hábitos e costumes.

Ao refletirem a respeito da existência de uma articulação entre os princípios do MST e os referenciais adotados pela EJA da escola do sistema de ensino a que se vinculam, os professores assentados se reportam às Matrizes Pedagógicas do MST, repensando como essas se relacionam com suas práticas na EJA.

Eu conheço as matrizes pedagógicas. Já li algumas coisas relacionadas aos objetivos dessas matrizes e percebo que muito do que a gente faz está lá na Pedagogia da luta social. Tudo o que faço tem uma finalidade que é ajudar os meus alunos na luta pelos direitos. Isso eu faço sem precisar ler em nenhum autor. Faço porque sei que é preciso. Mas prometo que vou estudar mais sobre essas matrizes. (Professora AI).

Olhe, infelizmente não são dadas a nós, professores assentados as oportunidades de estudar os referenciais do Movimento. A gente fica muito distante das discussões do MST em virtude de precisarmos atender as diretrizes educacionais da escola municipal. (Professora MV)

\section{SABERES FORMATIVOS DE PROFESSORES ASSENTADOS E ELABORAÇÃO CURRICULAR DA EJA}

Os depoimentos expressam as tensões que constituem o desafio a ser superado quando se trata das limitações que permeiam a trajetória da formação dos professores do campo no tocante à dicotomia que ainda prevalece na organização curricular - que coloca para os educadores a contradição entre atender um paradigma educacional linear e fechado ou articular à escola a materialidade concreta da luta pela terra e por direitos, empreendida pelos povos do campo, neste caso de um campo inserido no movimento social. (MOLINA, 2014). É apontada também a ausência no âmbito profissional de um espaço dialógico, que valorize os princípios pedagógicos do MST, 
sendo negadas as experiências que os professores constroem coletivamente no movimento social em que estão inseridos.

Conforme Caldart (2004), as matrizes pedagógicas definidas pelo MST se constituem em oito: pedagogia da luta social; pedagogia da organização coletiva; pedagogia da terra; pedagogia do trabalho e da produção; pedagogia da cultura; pedagogia da escolha; pedagogia da história; e pedagogia da alternância. Dada à relevância destes princípios pedagógicos na formação política e social do Movimento, pode-se compreender a necessidade de aproximações existentes entre esses princípios e o currículo da EJA, a partir das ações dos professores em propostas educativas que abordem especificidades da formação escolar de jovens e adultos do campo.

Entretanto, como apontado, os professores assentados, enquanto sujeitos engajados na luta coletiva de suas comunidades, enfrentam muitas dificuldades na tentativa de consolidarem uma prática educativa emancipadora nas escolas em que atuam. Entre as dificuldades vivenciadas, deparam-se com o desafio de elaborarem propostas educativas que considerem também os saberes advindos do MST, configurando uma prática educativa que difira de outras vigentes e estabeleça vínculos com os princípios políticos e pedagógicos do movimento social. O saber construído na luta pela terra ao ser tensionado frente às práticas educativas tradicionais provoca a construção de novos saberes, os quais impulsionam práticas transformadoras.

É nessa contradição que a prática dos professores assentados se move, ora se aproximando, ora se distanciando da perspectiva de uma educação emancipadora. A contradição, por ser inerente à cultura e à construção do conhecimento e por produzir a dissonância em nossos pensamentos, ideias e valores, nos compele a pensar, reavaliar e criticar. Se não fôssemos capazes de transitar por crenças e valores contraditórios seria impossível criar e manter qualquer cultura humana (PINHEIRO, 2007). Ao nos depararmos com a oscilação dos professores entre os referenciais curriculares que orientam suas práticas, com dois fundamentos distintos, é possível entendê-los melhor em uma visão panorâmica da realidade, examinando o desenvolvimento em termos de possibilidade de uma nova unidade.

Nesta possibilidade, o ser professor em uma escola inserida no movimento social exige desses professores a mobilização de um arsenal de saberes que os qualifica como tais, com trajetória pessoal e profissional que difere em virtude de uma prática educativa essencialmente política e da busca incessante de melhorias para a vida no assentamento. As relações que os professores constroem na militância do Movimento possibilitam um resgate do seu papel social e o desenvolvimento de uma prática com dimensões diversas, enquanto sujeitos comprometidos com um saber socialmente relevante. 
Nas tensões e dilemas dos professores com suas crenças e valores na construção de uma proposta curricular com referenciais institucionalizados, deve haver uma ressignificação essencialmente conceitual e imbricada no discurso freireano que transcende o pedagógico e se situa no ato político. Nesta consonância, Freire (et Alii, 1986, p. 76) ressalta que “[...] a natureza do processo educativo sempre é diretiva, não importa se a educação é feita pela burguesia ou pela classe trabalhadora”. Nesta ótica, os professores enquanto mediadores de um processo educativo diretivo, no qual os sujeitos educandos tiveram seus direitos negados, não podem se omitir de suas responsabilidades no tocante à construção dos referenciais que norteiam suas práticas educativas.

Ah, os meus saberes eu valorizo e muito. Tanto os de professora como os da luta como assentada. Quando falamos das nossas experiências no MST e depois que nos tornamos assentados todos os alunos querem fazer um relato... lembram das dificuldades... eles gostam muito e, por eles, a gente ficava conversando o resto da aula... Agora, tem uma hora que a gente tem que entrar com os conteúdos e aí eles ficam observando, em silêncio, como se não tivessem gostando muito, mas temos que ensinar outras coisas a eles, né? (Professora MS)

O depoimento aponta para uma integração entre os saberes e a realidade contextual de suas práticas na EJA, na relação da identidade profissional dos educadores e o perfil dos sujeitos educandos. No entanto, apesar de os professores manifestarem entender a importância dos saberes no currículo, na fala da professora MS se percebe a dificuldade que os mesmos ainda encontram quando se trata de articularem, em suas práticas, os conteúdos sistematizados às trajetórias pessoais dos sujeitos. Essa dificuldade pode estar enraizada na dualidade conceitual que ainda persiste nas propostas educativas lineares que influenciam os professores a optarem entre a seleção ou a exclusão de conhecimentos que possuem, em sua ótica, maior ou menor valor cultural.

Ao pensar em como integrar os saberes em suas práticas, os professores assentados podem propiciar condições para que os sujeitos jovens e adultos, em suas relações uns com os outros e todos com o professor, exercitem a experiência de sua constituição social. No debate acerca da integração dos saberes e das vivências, os professores dialogam a respeito da inserção dos saberes advindos do MST e quanto à dinâmica das aulas e das relações estabelecidas por meio da partilha de histórias de vida dos sujeitos educandos.

Dou muita atenção quando eles relatam sobre os problemas enfrentados em nosso assentamento e na associação, as questões da falta de apoio para a agricultura, para o tempo das estiagens e até quando estão preocupados com os recursos financeiros da reforma agrária, do Pronaf. Outro dia na aula a gente elaborou uma carta para o banco falando do seguro Safra que estava demorando muito. (Professora MV).

Aqui na escola é quase impossível a gente não trazer para a sala de aula as experiências do MST, pois temos muitas vezes que compreender muitas coisas que vivem nossos alunos... por exemplo, 
quando eu passo uma atividade e o aluno não faz por que foi trabalhar no lote? Eu tenho que arranjar um jeito dele não perder aquele conteúdo, o assunto que passei... (Professor JM).

A professora MV expressa o cuidado e a atenção dispensados em sua prática aos educandos assentados, reconhecendo as adversidades enfrentadas por estes quando da garantia dos seus direitos quase sempre negados. Esta professora partilha desta mesma realidade enquanto assentada e sua atitude ultrapassa os limites de uma ação pedagógica, se complementando na relação de proximidade e de solidariedade estabelecidas entre os sujeitos educandos e os professores assentados. Esta conexão constitui um elemento da prática pedagógica que se diferencia das demais em virtude dos laços de amizade e de confiança construídos em um contexto de resistência e sobrevivência.

Nesta prática, no que se refere à existência de duas lógicas distintas que norteiam a organização curricular da EJA, constata-se que a concepção institucionalizada, presente nos referenciais curriculares encaminhados pela Secretaria Municipal de Educação, representa os interesses do Estado. Diferencialmente das determinações curriculares prescritas por esse organismo, emerge a do movimento social, a qual possibilita a leitura de mundo, a problematização e a conectividade com o ideário educacional do MST. Em relação aos aspectos pertinentes ao envolvimento dos professores neste Movimento, é notório que desta participação emanam contribuições que diferenciam suas atuações quando se trata de uma prática voltada para os sujeitos jovens e adultos assentados. Princípios como criticidade, justiça social, dialogicidade e amorosidade permeiam as relações construídas conjuntamente dentro e fora do ambiente escolar. Os professores não somente atuam como mediadores da aprendizagem, mas também como facilitadores da inserção social das pessoas jovens e adultas na comunidade.

Todavia, a existência das duas lógicas coabitando um mesmo espaço educacional, com distanciamentos e descompassos na organização curricular da EJA e na prática dos professores, resultante do encontro e confronto de visões distintas, pode se converter em entrave na construção de uma perspectiva curricular crítica que atenda as demandas pessoais e profissionais dos alunos. As concepções que amparam a lógica institucionalizada se enraízam na perspectiva de educação compensatória que pensa esta modalidade de ensino como reposição do tempo escolar perdido, olhando apenas para o não acesso à escola, sem considerar suas especificidades. Esta tendência se ampara na perspectiva cartesiana que influenciou os processos de aquisição, construção e disseminação do conhecimento, sendo que a separação entre sujeito e objeto permaneceu como forte característica. (MORIN, 2000). 
A marca predominante nas propostas curriculares institucionais é a da fragmentação do conhecimento e a da organização do currículo sob a ótica cientificista e disciplinarista, que bloqueia o estabelecimento de diálogos entre experiências vividas, saberes anteriormente construídos e conteúdos escolares. Na escola locus desta investigação a realidade diversa de encontros e confrontos entre as lógicas distintas apresentadas estimula um movimento inverso à ordem curricular predominantemente estabelecida, proporcionando a superação dos modelos curriculares dominantes. Este movimento de natureza reflexiva e dialógica é percebido nos depoimentos dos professores, quando demonstram compreender as imposições curriculares presentes nos referenciais adotados pela escola e no desejo que possuem de ultrapassar as lacunas deixadas pelos documentos oficiais e construir propostas educativas que considerem as histórias de vida e as trajetórias escolares do povo campesino.

Portanto, apesar das dificuldades impostas por uma estrutura curricular tradicional e acrítica, os professores assentados atuam em uma construção mais ampla com um projeto educativo gestado por eles mesmos e amparados nos princípios educativos do MST. Esta postura se ampara na formação política identitária do Movimento e nos saberes e vivências advindos do cotidiano educativo que os capacitam para superarem as contradições e promoverem as transformações necessárias para a consolidação de uma EJA emancipadora na comunidade.

A existência de um processo educativo vinculado ao projeto político do MST, em consonância articulada com os referenciais da EJA da Secretaria Municipal, se configura como possibilidade no espaço educativo no qual a socialização e a partilha do ideário coletivo dos professores respondem as necessidades pessoais e profissionais dos sujeitos. Os vínculos sociais percebidos permitem o relacionar da prática educativa aos aspectos culturais presentes no cotidiano da EJA, dando visibilidade à cultura local e, nesta conformidade, é propício afirmar que a participação política dos professores no MST aponta para contribuições no tocante à articulação entre o ideal político do movimento social e a EJA de uma escola pública.

As reflexões empreendidas acerca da prática educativa apontam para a assertiva da dialogicidade freireana, como ponte nas articulações curriculares construídas pelos professores e educandos no MST, e a busca por uma educação problematizadora na qual os sujeitos possam construir sua autonomia apesar das desarticulações presentes na educação de jovens e adultos. Esta noção concorre para que os desafios encontrados no cotidiano da prática na EJA sejam superados por meio de relações permeadas de solidariedade e respeito mútuo, como princípios que embasam a busca por uma educação crítica e integradora na escola do assentamento - que não seja apenas uma utopia na vida das pessoas jovens e adultas do campo. 


\section{REFERÊNCIAS}

APPLE, Michael W. Ideologia e Currículo. 3. ed. Porto Alegre: Artmed, 2006.

CALDART, Roseli Salete. Pedagogia do Movimento Sem Terra. 3. ed. São Paulo: Expressão Popular, 2004.

CARR, Wilfred; KEMMIS, Stephen. Teoria crítica de la ensenanza: la investigación-acción en la formación del professorado. Barcelona: Martinez Roca, 1988.

CHARLOT, Bernard. Da relação com o saber: elementos para uma teoria. Porto Alegre: Artes Médicas Sul, 2000

FREIRE, Paulo et al. Pedagogia: diálogo e conflito. 2. ed. São Paulo: Cortez, 1986.

Educação como prática da liberdade. Rio de Janeiro: Paz e Terra, 2007.

MOLINA, Mônica Castagna. Análises de práticas contra-hegemônicas na formação de educadores. In: SOUZA, José Vieira (Org.). O método dialético na pesquisa em educação. Campinas: Autores Associados, 2014.

MORIN, Edgar. Os sete saberes necessários à educação do futuro. 8. ed. São Paulo: Cortez, 2000

PAIVA, Jane. Educação de jovens e adultos: direitos, concepções e sentidos. Rio de Janeiro: DP et Alii, 2005.

PINHEIRO, Rosa Aparecida. Formação de educadores de jovens e adultos: relação entre saberes na proposição curricular. Natal: EDUFRN, 2007.

SILVA, Tomaz Tadeu. Documentos de identidade: uma introdução às teorias do currículo. 2. ed. Belo Horizonte: Autêntica, 2007.

SOUZA, Maria Antônia. Movimentos sociais no Brasil contemporâneo: participação no contexto das práticas democráticas. In: VIII Congresso Luso-Afro-Brasileiro de Ciências Sociais. Anais eletrônicos. Coimbra, 2004. Disp.: <http://www.ces.uc.pt/lab2004/pdfs/Maria AntoniaSouza.pdf>. Acesso: 10 fev. 2016. 


\section{RESUMO}

No âmbito da formação continuada, ao pensar as proposições curriculares para a educação de jovens e adultos (EJA), a partir da investigação de como nestas se articulam os saberes e vivências dos professores em um assentamento que atuam em uma escola pública municipal, em Florânia/Rio Grande do Norte (RN), - por meio de uma Pesquisa Colaborativa, reflete-se sobre a existência de duas lógicas que orientam a configuração curricular: uma encaminhada pela Secretaria Municipal de Educação; e, outra, advinda do Movimento dos Trabalhadores Rurais Sem-Terra (MST), com dinâmicas e propostas diferenciadas, buscando compreender as orientações e padrões em disputa, que possibilitam reconfigurar uma proposição curricular que contemple as necessidades dos jovens e adultos assentados.

Palavras chave: Formação; Currículo; Movimentos Sociais; Escola Pública.

\section{CURRÍCULUM, KNOWLEDGE AND LIFE EXPERIENCES OF TEACHERS OF YOUNG AND ADULTS EDUCATION: RECONFIGURATION OF EXPERIENCES IN SCHOOL IN A SETTLEMENT}

\section{ABSTRAT}

In the scope of continued formation, regarding the curricular propositions to the Education of Young and Adults, and through a collaborative investigation about how they are composed of merged knowledges and life experiences of the teachers who work at a municipal school in Florânia/RN, this article reflects upon the existence of two logics that guide the curricular configuration - one put forward by the municipality's office for Education and one that comes from a grassroots movement, the Landless Workers' Movement (MST). They have specific dynamics and proposals, and this article tries to understand the biases and patterns that are disputed during the reconfiguration of curricular proposals that contemplate the needs of the young and adults that live in the movement's settlement.

Keywords: Formation. Curriculum. Social Movements. Public School. 